Article

\title{
Parameter Space Design of a Guest-Host Liquid Crystal Device for Transmittance Control
}

\author{
Seung-Min Nam ${ }^{1}$, Seung-Won Oh ${ }^{1} \mathbb{D}$, Sang-Hyeok Kim ${ }^{1}$, Jae-Won Huh ${ }^{1} \mathbb{D}$, Eunjung Lim ${ }^{2}$, \\ Jinhong $\mathrm{Kim}^{2}$ and Tae-Hoon Yoon ${ }^{1, *(D)}$ \\ 1 Department of Electronics Engineering, Pusan National University, Busan 46241, Korea; \\ skad007@pusan.ac.kr (S.-M.N.); ohseungwon@pusan.ac.kr (S.-W.O.); xenath@pusan.ac.kr (S.-H.K.); \\ ijwhuh@pusan.ac.kr (J.-W.H.) \\ 2 LG Chem R\&D Campus Daejeon, Daejeon 34122, Korea; limej@lgchem.com (E.L.); \\ jinhongkim@lgchem.com (J.K.) \\ * Correspondence: thyoon@pusan.ac.kr
}

Received: 4 December 2018; Accepted: 22 January 2019; Published: 26 January 2019

\begin{abstract}
A transmittance-control device requires a high transmittance difference between its transparent and opaque states. In this paper, we propose a systematic approach to find the condition for the maximum transmittance difference in a guest-host liquid crystal (GHLC) cell. To this end, we calculated the transmittance difference as we varied the cell gap and dye concentration. The transmittance of a GHLC cell is dependent on the alignment of dye molecules, cell gap, and dye concentration. We used a constant-transmittance contour map to find the condition for the desired transmittance of LC cells in each state and the transmittance difference of each LC mode. We experimentally confirmed that the design of a GHLC cell with the desired performance could be achieved through the proposed design process.
\end{abstract}

Keywords: transmittance-control device; liquid crystal; guest-host liquid crystal; dichroic dye

\section{Introduction}

Transmittance-control devices allow users to control the intensity of transmitted light through the absorption of incident light. Electrochromic devices (ECD) [1-4], suspended particle devices (SPD) [5,6], and liquid crystal (LC) devices [7-13] have been studied to control the transmittance of eyewear, smart windows, and automotive applications. ECD and SPD have been widely used because of their low transmittance in the opaque state. Although they have been studied extensively, they are not able to demonstrate color neutrality, adequate durability, a low manufacturing cost, and a fast switching speed at the same time, which limits their practical application. In particular, they may be inadequate for applications requiring a fast switching speed for safety because of their long response times, which range from several minutes to several hours. LC devices can be used for such applications because they have a fast response time of several tens of milliseconds.

A guest-host LC (GHLC) cell consists of host LCs and guest dichroic dyes, which are convenient for the switching of dichroic dyes [14-19]. Dichroic dyes can be easily aligned along the alignment direction of the LC molecules [20,21]. Owing to their dichroism, dye molecules strongly (weakly) absorb the incident light polarized parallel (perpendicular) to their absorption axis. The transmittance of a GHLC cell is dependent on the alignment of the dye molecules, the absorption coefficient of the dye, cell gap, and dye concentration. By increasing the cell gap or dye concentration, the transmittance in the opaque state can be lowered, but that in the transparent state is also lowered. Moreover, the response time and the driving voltage of a GHLC cell are dependent on the cell gap and dye concentration, and the solubility of the dye molecule can be an issue [22-24]. Therefore, it is necessary 
to find the condition that gives the maximum transmittance difference between the transparent and opaque states while satisfying the desired performance, such as the response time and driving voltage, and without the solubility issue.

In this study, we present a systematic approach to finding the condition for the desired transmittance difference in a GHLC device. We calculated the transmittance difference as we varied the cell gap and dye concentration. The transmittance is dependent on the alignment of LC and dye molecules in a GHLC cell. Thus far, the trial-and-error method has been used to find the condition for the desired GHLC cell. In the proposed process, however, we can determine the conditions of the cell gap and dye concentration with the desired performance, such as the transmittance in the transparent state, transmittance difference, driving voltage, and response time. Therefore, by using the proposed process, we can systematically obtain the condition for the desired GHLC cell before cell fabrication. We expect that the proposed approach will offer an effective method for the fabrication of a GHLC cell that can be used to control transmittance.

\section{Experimental and Calculation Conditions}

The LC parameters used for the experiments and calculations are as follows: the birefringence $\Delta n$ $=0.1169$; the dielectric anisotropy $\Delta \varepsilon=7$; the elastic constants $K_{11}=13.1 \mathrm{pN}, K_{22}=5.95 \mathrm{pN}$, and $K_{33}=$ $13.6 \mathrm{pN}$; and the rotational viscosity $\gamma_{1}=61 \mathrm{mPa} \cdot \mathrm{s}$. To achieve the absorption of the incident light, the LCs were mixed with a black dichroic dye X12 (BASF, Ludwigshafen, Germany). The measured absorption coefficients $\alpha_{\|}$and $\alpha_{\perp}$ were $27.28 \mu \mathrm{m}^{-1}$ and $3.560 \mu \mathrm{m}^{-1}$ at $550 \mathrm{~nm}$, respectively, and the dichroic ratio was 7.663 at $550 \mathrm{~nm} . \alpha_{\|}$and $\alpha_{\perp}$ represent the absorption coefficients of the dye for polarization parallel and perpendicular to the absorption axis of the dye molecules, respectively. The absorption coefficient of the dye was measured at room temperature with a GHLC cell with the cell gap of $10 \mu \mathrm{m}$ and the dye concentration of $1 \mathrm{wt} \%$. The saturation concentration is the maximum concentration of the solution (dye) that can be dissolved in a solvent (LC). The saturation concentration of the dye X12 in the used LC was about $3.5 \mathrm{wt} \%$.

To fabricate electrically controlled birefringence (ECB) and cholesteric LC (ChLC) cells, we used the homogeneous alignment layer (PIA-X610-33C, JNC Corporation, Tokyo, Japan), and the substrates were baked for $1 \mathrm{~h}$ at $220^{\circ} \mathrm{C}$. For the ChLC cell, the chiral dopant (S811, Merck, Darmstadt, Germany) were mixed additionally. To prevent waveguiding and Bragg reflection in the visible region, the pitch was set to $1.3 \mu \mathrm{m}$ and the amount of chiral dopant was chosen to form a pitch of $1.3 \mu \mathrm{m}$ [25].

\section{The Transmittance of Guest-Host Liquid Crystal Cells}

The transmittance of a homogeneously-aligned LC cell for polarization parallel and perpendicular to the absorption axis of the dye molecules can be described as

$$
\begin{aligned}
& T_{\|}=T_{0} \exp \left(-\alpha_{\|} c d\right) \\
& T_{\perp}=T_{0} \exp \left(-\alpha_{\perp} c d\right)
\end{aligned}
$$

where $T_{\|}$and $T_{\perp}$ are the transmittances of a GHLC cell for polarization parallel and perpendicular to the absorption axis of the dye molecules, respectively. $T_{0}$ is the transmittance of a homogeneously aligned LC cell without a dye. $c$ is the dye concentration and $d$ is the cell gap [26,27].

In the homeotropic state, the dye molecules are aligned perpendicular to the substrates so that this state is transparent. In the twisted state, the dye molecules absorb incident light regardless of the polarization direction. The transmittance in the homeotropic, homogeneous, and twisted states can be expressed as

$$
\begin{gathered}
T_{\text {homeo }}=T_{0}\left[\exp \left(-\alpha_{\perp} c d\right)\right] \\
T_{\text {homo }}=\frac{T_{0}}{2}\left[\exp \left(-\alpha_{\|} c d\right)+\exp \left(-\alpha_{\perp} c d\right)\right]
\end{gathered}
$$




$$
T_{\text {twist }}=T_{0}\left[\exp \left(-\frac{\alpha_{\|}+\alpha_{\perp}}{2} c d\right)\right]
$$

where $T_{\text {homeo }}, T_{\text {homo }}$, and $T_{\text {twist }}$ represent the transmittances of the homeotropic, homogeneous, and twisted states, respectively.

We first calculated the transmittance of each state using Equation (2) as we varied the cell gap and dye concentration. To compare the measured results with the calculated ones, we fabricated ECB and ChLC cells. To determine the effect of the dye concentration, the dye concentration was changed from 0 to $6 \mathrm{wt} \%$ at a fixed cell gap of $10 \mu \mathrm{m}$. To confirm the effect of the cell gap, the cell gap was changed from 0.5 to $30 \mu \mathrm{m}$ at a fixed dye concentration of $1 \mathrm{wt} \%$. The transmittance of the LC cell in the homeotropic, homogeneous, and twisted states decreases as the dye concentration or cell gap is increased, as shown in Figure 1. The twisted state shows a lower transmittance than the homogeneous state because twisted LC and dye molecules absorb the incident light regardless of the polarization direction. The measured transmittance values tend to match the calculated values, which means that the calculated results are reliable. However, the measured results are different from the calculated ones when the dye concentration is higher than $4 \mathrm{wt} \%$, as shown in Figure 1a. This is due to the saturation of the dye molecules, as all of them do not dissolve when the concentration is higher than the saturation concentration.
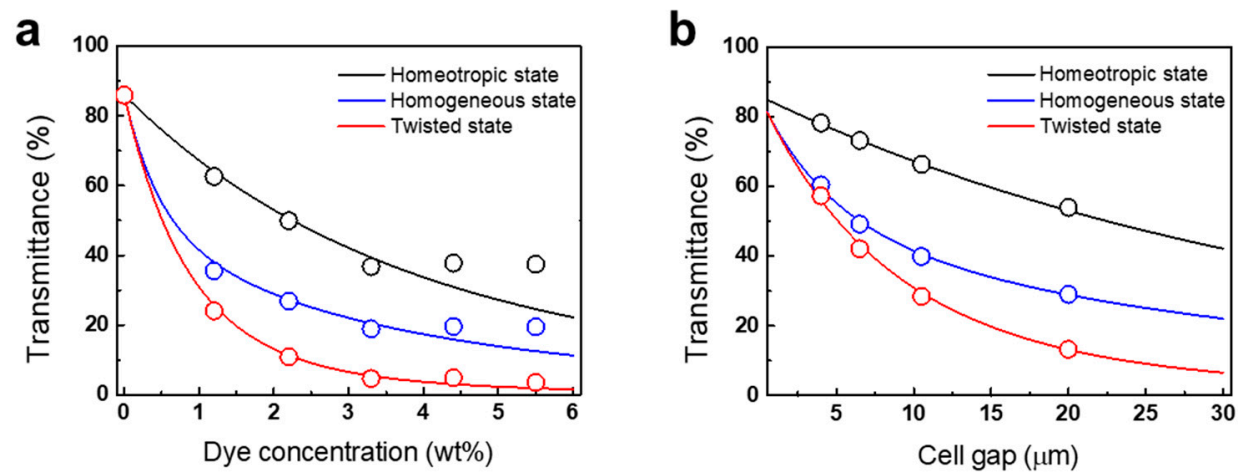

Figure 1. The calculated (solid line) and measured (empty circle) transmittances of LC cells as functions of the (a) dye concentration and (b) cell gap.

We plotted the constant-transmittance contour maps of an LC cell in each state on the parameter space of the cell gap and dye concentration. Figure 2 shows the constant-transmittance contour maps of LC cells in the homeotropic, homogeneous, and twisted states. For applications requiring a high transmittance in the transparent state, a low dye concentration and thin cell gap should be selected within the desired region. For applications requiring a low transmittance in the opaque state, a high dye concentration and thick cell gap should be selected within the desired region. These results can be useful for designing a GHLC cell when there is a requirement for the minimum allowable transmittance of the transparent state or the maximum allowable transmittance of the opaque state.
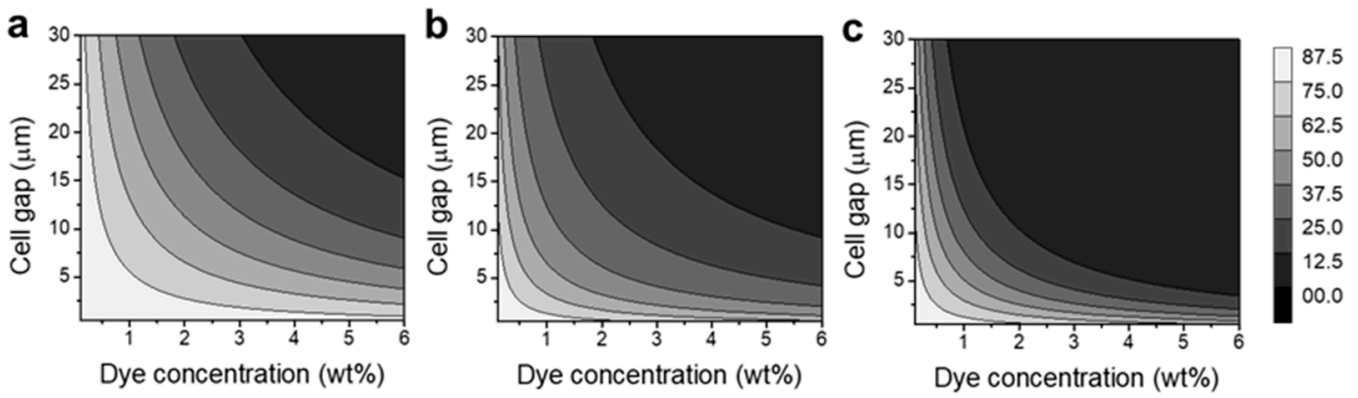

Figure 2. The constant-transmittance contour maps of LC cells in the (a) homeotropic, (b) homogeneous, and (c) twisted states on the parameter space of the dye concentration and cell gap. 
An ECB cell uses the homeotropic and homogeneous states as the transparent and opaque states, respectively, as shown in Figure 3a. In a ChLC cell, the homeotropic state is used as a transparent state, while the twisted state is used as an opaque state, as shown in Figure $3 b$. The transmittance difference of ECB and ChLC cells can be expressed as follows by using Equation (2):

$$
\begin{gathered}
\Delta T_{E C B}: T_{\text {homeo }}-T_{\text {homo }}=\frac{T_{0}}{2} \exp \left(-\alpha_{\|} c d\right)(1-\exp (\Delta \alpha c d)) \\
\Delta T_{\text {ChLC }}: T_{\text {homeo }}-T_{\text {twist }}=T_{0} \exp \left(-\frac{\alpha_{\|}+\alpha_{\perp}}{2} c d\right)\left(1-\exp \left(\frac{\Delta \alpha}{2} c d\right)\right)
\end{gathered}
$$

where $\Delta T_{E C B}$ and $\Delta T_{C h L C}$ represent the transmittance differences of ECB and ChLC cells, respectively. $\Delta \alpha$ represents the difference between the absorption coefficients in the directions parallel and perpendicular to the absorption axis of dye molecules, that is, $\alpha_{\|}-\alpha_{\perp}$.
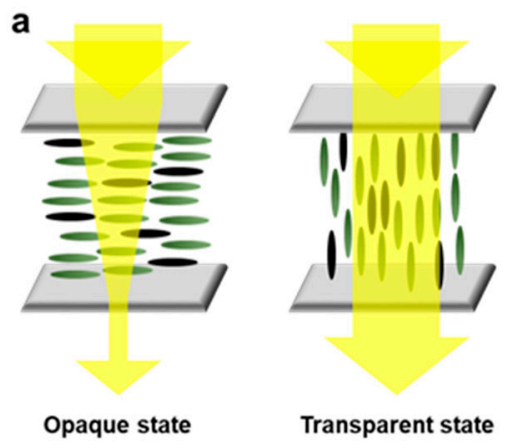

b

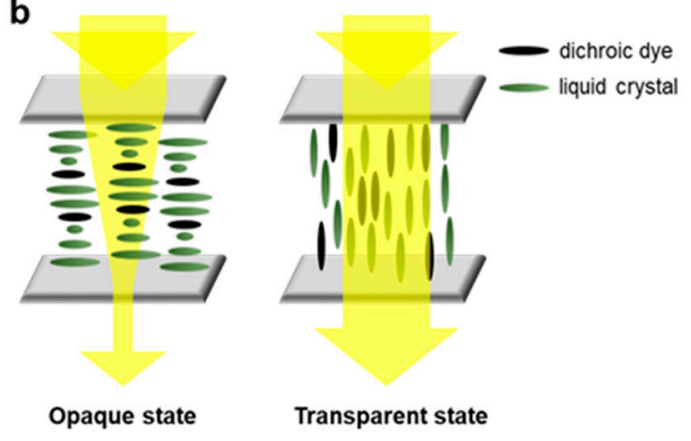

Figure 3. The schematic representation of (a) ECB and (b) ChLC cells.

Using Equation (3), we calculated the transmittance difference between the transparent and opaque states as a function of dye concentration and cell gap. The maximum transmittance difference of a ChLC cell is higher than that of an ECB cell because of its lower transmittance in an opaque state, as shown in Figure 4. The condition for achieving the maximum transmittance difference is dependent on the LC mode. The dye concentrations (cell gap) for the ECB and ChLC cells were around $1.2 \mathrm{wt} \%$ and $1.7 \mathrm{wt} \%(12 \mu \mathrm{m}$ and $17 \mu \mathrm{m})$, respectively. For a dye concentration of over $4 \mathrm{wt} \%$, the measured transmittance difference was higher than the calculated value because the dye molecules were not dissolved completely in the LC, as shown in Figure 4a. These insoluble dye molecules may crystallize in the cell and can cause stability issues [24].
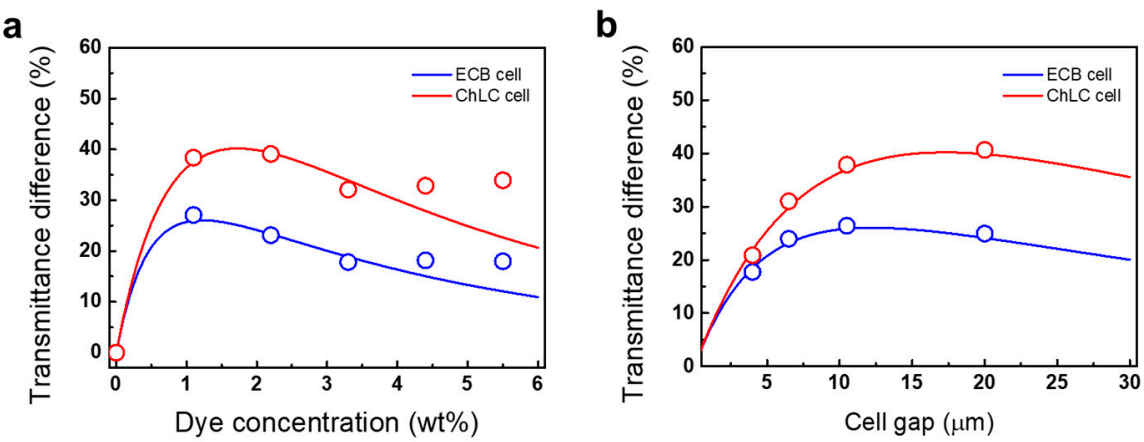

Figure 4. The calculated (solid line) and measured (empty circle) transmittance differences of ECB and ChLC cells as functions of the (a) dye concentration and (b) cell gap.

We plotted the constant transmittance-difference contour maps of each LC mode on the parameter space of the cell gap and dye concentration, as shown in Figure 5. Because the transmittance difference increases and then decreases as the cell gap or dye concentration increases, we can find the region in 
which the transmittance difference of a GHLC cell is higher than the desired value. An ECB cell cannot provide a transmittance difference higher than $30 \%$, while a ChLC cell can provide a transmittance difference of up to $42 \%$. Although our results show that a ChLC cell has a higher transmittance difference than an ECB cell, we should note that the choice of the LC mode depends on the application. A ChLC cell can have drawbacks such as a complicated drive scheme, high driving voltage, and slow response $[25,28,29]$. Moreover, when designing a ChLC cell, the optimization of dye concentration is required because a ChLC cell fabricated with a commercial black dye has a color issue [30]. Therefore, we should carefully choose the mode for an application to achieve the desired performance.
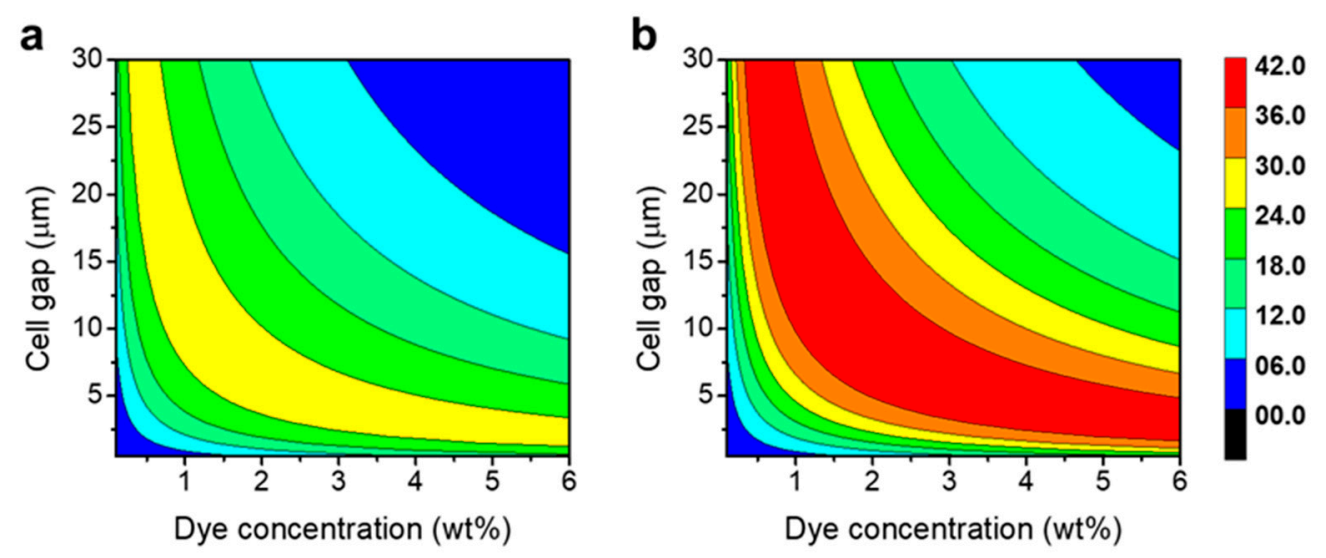

Figure 5. The constant transmittance-difference contour maps of (a) ECB and (b) ChLC cells on the parameter space of the cell gap and dye concentration.

\section{Design and Fabrication Process}

In this chapter, we introduce how to design and fabricate a GHLC cell. The design and fabrication process is as follows: i) Choose the appropriate LC mode considering the application; ii) exclude the conditions that cannot satisfy the minimum transmittance in the transparent state; iii) determine the maximum cell gap considering the response time or driving voltage and the maximum dye concentration, considering the saturation concentration of the dye to be mixed with the used LCs; and iv) select the condition for the maximum transmittance difference in a constant transmittance-difference contour map.

For a better understanding of the above process, we designed and fabricated GHLC cells with a decay time of less than $30 \mathrm{~ms}$ and a transmittance in the transparent state of higher than $50 \%$. For short response times, we chose the ECB mode for a GHLC cell. We plotted a constant transmittance-difference contour map of an ECB cell for the design process, as shown in Figure 6a. Next, we excluded the condition that the transmittance in the transparent state is lower than $50 \%$ in the contour map, as shown in Figure 6b. We excluded the condition that the dye concentration is higher than $3.5 \mathrm{wt} \%$ and the cell gap is higher than $8 \mu \mathrm{m}$ because the saturation concentration of the dye is $3.5 \mathrm{wt} \%$ and the cell gap should be lower than $8 \mu \mathrm{m}$ for a decay time $\left[\tau_{d}=\left(\gamma_{1} / K_{11}\right) \cdot(d / \pi)^{2}\right]$ shorter than $30 \mathrm{~ms}$, as shown in Figure 6c [31]. Finally, we chose one of the conditions in the yellow-colored region of Figure $6 \mathrm{~d}$, where the transmittance difference is higher than $24 \%$. To ensure that the fabricated ECB cells can provide the desired performance, three samples were fabricated under the different conditions within the yellow-colored region of Figure $6 \mathrm{~d}$. The dye concentration and cell gap of each sample were $c=1.5 \mathrm{wt} \%$ and $d=6.5 \mu \mathrm{m}$ for sample $1 ; c=2.25 \mathrm{wt} \%$ and $d=5.5 \mu \mathrm{m}$ for sample 2 ; and $c=3 \mathrm{wt} \%$ and $d=4.5 \mu \mathrm{m}$ for sample 3 . 

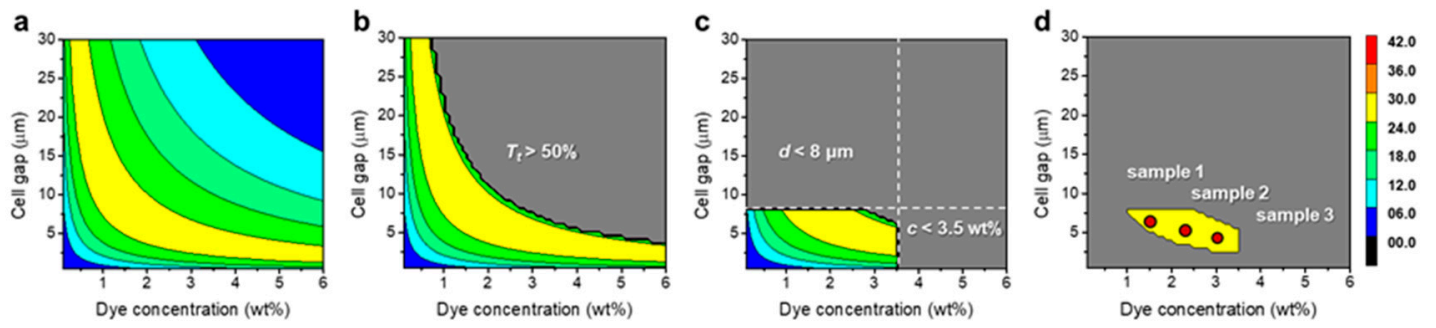

Figure 6. An example of the proposed design process for an ECB cell on a constant transmittance-difference contour map. (a) The constant transmittance-difference contour map of an ECB cell. (b) The region that does not satisfy the minimum transmittance in the transparent state is excluded. (c) The regions that do not satisfy the conditions of the cell gap and dye concentration are excluded. (d) The regions that do not satisfy the minimum transmittance difference are excluded. The red dots represent the fabrication condition for the 3 samples.

The transmittance difference $(\Delta T)$, transmittance in the transparent state $\left(T_{t}\right)$, decay time $\left(\tau_{d}\right)$, rise time $\left(\tau_{r}\right)$, and driving voltage $\left(V_{d}\right)$ of the fabricated ECB cells are summarized in Table 1 . For all three samples, the results satisfied the desired performance. The transmittance difference of all the samples was higher than $24 \%$, the transmittance in a transparent state was higher than $50 \%$, and the decay time was less than $30 \mathrm{~ms}$. The response time increased as the cell gap was increased. However, there was no dependence of the response time on the dye concentration.

Table 1. The measured transmittance difference $\Delta T$, transmittance in the transparent state $T_{t}$, and the decay time $\tau_{d}$, rise time $\tau_{r}$, and driving voltage $V_{d}$ of the fabricated ECB cells.

\begin{tabular}{cccccccc}
\hline & $\boldsymbol{d}(\boldsymbol{\mu \mathrm { m } )}$ & $\boldsymbol{c}(\mathbf{w t} \boldsymbol{\%})$ & $\boldsymbol{\Delta T} \mathbf{( \% )}$ & $\boldsymbol{T}_{\boldsymbol{t}} \mathbf{( \% )}$ & $\boldsymbol{\tau}_{\boldsymbol{d}}(\mathbf{m s})$ & $\boldsymbol{\tau}_{\boldsymbol{r}}(\mathbf{m s})$ & $\boldsymbol{V}_{\boldsymbol{d}}(\mathrm{V})$ \\
\hline Sample 1 & 6.5 & 1.5 & 25.8 & 60.4 & 14.1 & 0.54 & 12.5 \\
Sample 2 & 5.5 & 2.25 & 26.0 & 62.8 & 12.9 & 0.46 & 12.5 \\
Sample 3 & 4.5 & 3.0 & 25.7 & 67.6 & 9.5 & 0.41 & 12.5 \\
\hline
\end{tabular}

As another example, we also designed and fabricated a GHLC cell with a driving voltage lower than $40 \mathrm{~V}$ and a transmittance in the transparent state higher than $50 \%$. For a high transmittance difference, we chose a ChLC cell that had the lowest transmittance in the opaque state. We plotted a constant transmittance-difference contour map of a ChLC cell for the design process, as shown in Figure 7a. We then excluded the condition in which the transmittance in the transparent state is less than $50 \%$ in the contour map, as shown in Figure $7 \mathrm{~b}$. We excluded the condition where the dye concentration is higher than $3.5 \mathrm{wt} \%$ and the cell gap is higher than $15 \mu \mathrm{m}$ because the saturation concentration of the dye is $3.5 \mathrm{wt} \%$, yet the cell gap should be less than $15 \mu \mathrm{m}$ for a driving voltage lower than $40 \mathrm{~V}[28,29]$, as shown in Figure 7c. Finally, we chose one of the conditions in the red-colored region of Figure $7 \mathrm{~d}$, where the transmittance difference is higher than $36 \%$. To make sure that a GHLC cell with the desired performance could be fabricated, three samples were fabricated under the different conditions within the red-colored region of Figure $7 \mathrm{~d}$. The dye concentration and cell gap of each sample were as follows: $c=1.5 \mathrm{wt} \%$ and $d=10 \mu \mathrm{m}$ for sample $1 ; c=2 \mathrm{wt} \%$ and $d=6.5 \mu \mathrm{m}$ for sample 2 ; and $c=3 \mathrm{wt} \%$ and $d=4.5 \mu \mathrm{m}$ for sample 3 . 

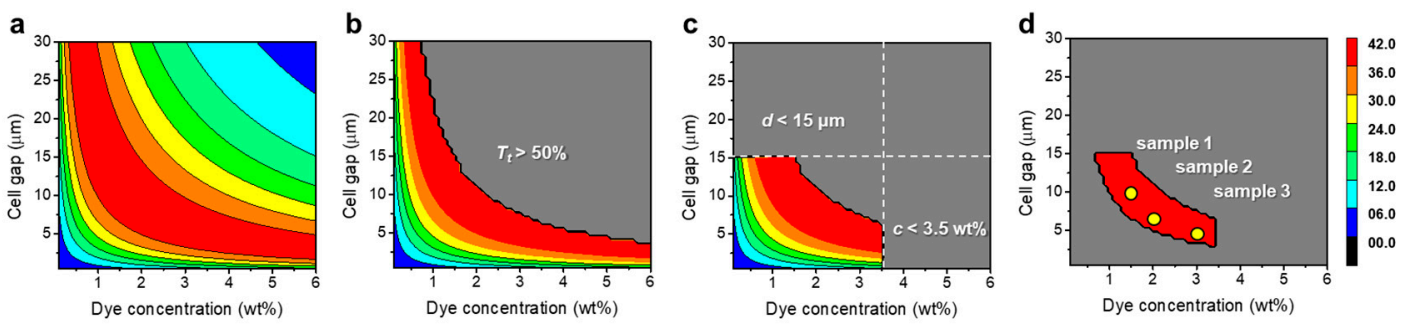

Figure 7. An example of the proposed design process for a ChLC cell on a constant transmittance-difference contour map. (a) The constant transmittance-difference contour map of a ChLC cell. (b) The region that does not satisfy the minimum transmittance in the transparent state is excluded. (c) The regions that do not satisfy the conditions of the cell gap and dye concentration are excluded. (d) The regions that do not satisfy the minimum transmittance difference are excluded. The yellow dots represent the fabrication condition for the 3 samples.

The transmittance difference $(\Delta T)$, transmittance in the transparent state $\left(T_{t}\right)$, decay time $\left(\tau_{d}\right)$, rise time $\left(\tau_{r}\right)$, and driving voltage $\left(V_{d}\right)$ of the fabricated ChLC cells are summarized in Table 2 . For all the three samples, the measured results satisfied the desired performance. The transmittance difference was higher than $36 \%$, the transmittance in the transparent state was higher than more than $50 \%$, and the driving voltage was lower than $40 \mathrm{~V}$. The decay times of the ChLC cells are too slow to be used for applications requiring a fast response time.

Table 2. The measured transmittance difference $\Delta T$, transmittance in the transparent state $T_{t}$, decay time $\tau_{d}$, rise time $\tau_{r}$, and driving voltage $V_{d}$ of the fabricated ChLC cells.

\begin{tabular}{cccccccc}
\hline & $\boldsymbol{d}(\boldsymbol{\mu \mathrm { m } )}$ & $c(\mathbf{w t} \boldsymbol{\%})$ & $\boldsymbol{\Delta} \boldsymbol{T}(\mathbf{\%})$ & $\boldsymbol{T}_{\boldsymbol{t}}(\mathbf{\%})$ & $\tau_{\boldsymbol{d}}(\mathbf{m s})$ & $\tau_{\boldsymbol{r}}(\mathbf{m s})$ & $V_{\boldsymbol{d}}(\mathrm{V})$ \\
\hline Sample 1 & 10 & 1.5 & 40.0 & 58.7 & 452 & 1.6 & 35.0 \\
Sample 2 & 6.5 & 2.0 & 39.1 & 62.4 & 385 & 1.6 & 21.0 \\
Sample 3 & 4.5 & 3.0 & 39.2 & 62.2 & 295 & 1.5 & 14.0 \\
\hline
\end{tabular}

We confirmed that all the fabricated GHLC cells satisfy the desired performance, such as fast response and high transmittance difference. We could systematically design a GHLC cell with the desired parameters through the proposed process.

\section{Conclusions}

In this study, we demonstrated a systematic approach for designing GHLC cells with the desired performance, such as a specific transmittance difference, transmittance in the transparent state, driving voltage, and response time. Once the parameters of LCs and dyes are given, the design of a GHLC cell with the desired performance can be easily achieved by confining regions in a constant transmittance-difference contour map. For the confirmation of the proposed approach, we fabricated GHLC cells with a specific condition, and we found that the experimental results satisfied the desired performance.

Author Contributions: S.-M.N., S.-W.O., and T.-H.Y. planned the study. S.-M.N. wrote the manuscript; S.-M.N., S.-W.O. and J.-W.H. conceived and designed the guest-host liquid crystal cell. S.-M.N., S.-H.K. and J.K. performed the experiments; S.-M.N., S.-W.O. and E.L. analyzed the experimental and calculated data; T.-H.Y. supervised the analysis and co-wrote the manuscript. All authors discussed the results and also commented on the manuscript at all stages.

Funding: This work was supported by the National Research Foundation of Korea (NRF) grant funded by the Korea government (MSIP) (No. 2017R1A2A1A05001067).

Conflicts of Interest: The authors declare no conflicts of interest. 


\section{References}

1. Granqvist, C.G.; Wittwer, V. Materials for solar energy conversion: An overview. Sol. Energy Mater. Sol. Cells 1998, 54, 39-48. [CrossRef]

2. Granqvist, C.G. Oxide electrochromics: An introduction to devices and materials. Sol. Energy Mater. Sol. Cells 2012, 99, 1-13. [CrossRef]

3. Jensen, J.; Hösel, M.; Dyer, A.L.; Kerbs, F.C. Development and manufacture of polymer-based electrochromic devices. Adv. Funct. Mater. 2015, 25, 2073-2090. [CrossRef]

4. Xia, X.; Ku, Z.; Zhou, D.; Zhong, Y.; Zhang, Y.; Wang, Y.; Huang, M.J.; Tu, J.; Fan, H.J. Perovskite solar cell powered electrochromic batteries for smart windows. Mater. Horiz. 2016, 3, 588-595. [CrossRef]

5. Vergaz, R.; Sanchez-Pena, J.M.; Barrios, D.; Vazquez, C.; Contreras- Lallana, P. Modelling and electro-optical testing of suspended particle devices. Sol. Energy Mater. Sol. Cells 2008, 92, 1483-1487. [CrossRef]

6. Barrios, D.; Vergaz, R.; Sanchez-Pena, J.M.; Garcia-Camara, B.; Granqvist, C.G.; Niklasson, G.A. Simulation of the thickness dependence of the optical properties of suspended particle devices. Sol. Energy Mater. Sol. Cells 2015, 143, 613-622. [CrossRef]

7. Yoo, S.-H.; Park, M.-K.; Park, J.-S.; Kim, H.-R. Enhanced adhesion and transmittance uniformity in laminated polymer-dispersed liquid crystal films. J. Opt. Soc. Korea 2014, 18, 753-761. [CrossRef]

8. Smith, G.W. Cure parameters and phase behavior of an ultraviolet-cured polymer-dispersed liquid crystal. Mol. Cryst. Liq. Cryst. 1991, 196, 89-102. [CrossRef]

9. White, D.L.; Taylor, G.N. New absorptive mode reflective liquid-crystal display device. J. Appl. Phys. 2003, 45, 4718. [CrossRef]

10. Oh, S.-W.; Baek, J.-M.; Heo, J.; Yoon, T.-H. Dye-doped cholesteric liquid crystal light shutter with a polymer-dispersed liquid crystal film. Dyes Pigments 2016, 134, 36-40. [CrossRef]

11. Gutierrez-Cuevas, K.G.; Wang, L.; Zheng, Z.; Bisoyi, H.K.; Li, G.; Tan, L.-S.; Vaia, R.A.; Li, Q. Frequency-driven self-organized helical superstructures loaded with mesogen-grafted silica nanoparticles. Angew. Chem. 2016, 128, 13284-13288. [CrossRef]

12. Wang, L.; Bisoyi, H.K.; Zheng, Z.; Gutierrez-Cuevas, K.G.; Singh, G.; Kumar, S.; Bunning, T.J.; Li, Q. Stimuli-directed self-organized chiral superstructures for adaptive windows enabled by mesogen-functionalized graphene. Mater. Today 2017, 20, 230-237. [CrossRef]

13. Li, Q. Liquid Crystals beyond Displays: Chemistry, Physics, and Applications; John Wiley \& Sons: Hoboken, NJ, USA, 2012.

14. Heilmeier, G.H.; Zanoni, L.A. Guest-host interactions in nematic liquid crystals. A new electro-optic effect. Appl. Phys. Lett. 1968, 13, 91-92. [CrossRef]

15. Huh, J.-W.; Yu, B.-H.; Heo, J.; Yoon, T.-H. Double-cell light shutter using long-pitch cholesteric liquid crystal cells. Appl. Opt. 2015, 54, 3792-3795. [CrossRef]

16. Huh, J.-W.; Ji, S.-M.; Heo, J.; Yu, B.-H.; Yoon, T.-H. Bistable light shutter using dye-doped cholesteric liquid crystals driven with crossed patterned electrodes. J. Disp. Technol. 2016, 8, 779-783. [CrossRef]

17. Baek, J.-M.; Oh, S.-W.; Kim, S.-H.; Yoon, T.-H. Fabrication of an initially-focal-conic cholesteric liquid crystal cell without polymer stabilization. Displays 2018, 52, 55-58. [CrossRef]

18. Huh, J.-W.; Kim, J.-H.; Oh, S.-W.; Ji, S.-M.; Yoon, T.-H. Ion-doped liquid-crystal cell with low opaque-state specular transmittance based on electro-hydrodynamic effect. Dyes Pigments 2018, 150, 16-20. [CrossRef]

19. Kim, S.-H.; Oh, S.-W.; Yoon, T.-H. Enhancement of absorption and haze with hybrid anchoring of dye-doped cholesteric liquid crystals. Opt. Express. 2018, 26, 14259. [CrossRef] [PubMed]

20. Uchida, T.; Katagishi, T.; Onodera, M.; Shibata, Y. Reflective multicolor liquid-crystal display. IEEE Trans. Electron Devices 1986, 33, 1207-1211. [CrossRef]

21. Huh, J.-W.; Yu, B.-H.; Heo, J.; Ji, S.-M.; Yoon, T.-H. Technologies for display application of liquid crystal light shutters. Mol. Cryst. Liq. Cryst. 2017, 664, 120-129. [CrossRef]

22. Yang, D.-K.; Wu, S.-T. Fundamentals of Liquid Crystal Devices; John Wiley \& Sons: Chichester, UK, 2006.

23. Wu, S.T.; Yang, D.-K. Reflective Liquid Crystal Displays; John Wiley \& Sons: New York, NY, USA, 2001.

24. Ivashchenko, A.V. Dichroic Dyes for Liquid Crystal Displays; CRC Press: London, UK, 1994.

25. Yu, B.-H.; Huh, J.-W.; Kim, K.-H.; Yoon, T.-H. Light shutter using dichroic-dye-doped long-pitch cholesteric liquid crystals. Opt. Express 2013, 21, 29332-29337. [CrossRef] [PubMed]

26. Swinehart, D.F. The beer-lambert law. J. Chem. Educ. 1962, 39, 333-335. [CrossRef] 
27. Scheffer, T.J. Optimized three-component dye mixtures for achromatic guest-host liquid-crystal displays. J. Appl. Phys. 1982, 53, 257. [CrossRef]

28. Yu, B.-H.; Huh, J.-W.; Heo, J.; Yoon, T.-H. Simultaneous control of haze and transmittance using a dye-doped cholesteric liquid crystal cell. Liq. Cryst. 2015, 42, 1460-1464. [CrossRef]

29. Kim, K.-H.; Song, D.H.; Shen, Z.-G.; Park, B.W.; Park, K.-H.; Lee, J.-H.; Yoon, T.-H. Fast switching of long-pitch cholesteric liquid crystal device. Opt. Express 2011, 19, 10174-10179. [CrossRef] [PubMed]

30. Ji, S.-M.; Oh, S.-W.; Jo, Y.-S.; Nam, S.-M.; Kim, S.-H.; Huh, J.-W.; Lim, E.; Kim, J.; Yoon, T.-H. Optimization of dye mixing for achromatic transmittance control with a dye-doped cholesteric liquid crystal cell. Dyes Pigment. 2019, 160, 172-176. [CrossRef]

31. Yeh, P.; Gu, C. Optics of Liquid Crystal Displays, 2nd ed.; John Wiley \& Sons: Hoboken, NJ, USA, 2010.

(c) 2019 by the authors. Licensee MDPI, Basel, Switzerland. This article is an open access article distributed under the terms and conditions of the Creative Commons Attribution (CC BY) license (http:// creativecommons.org/licenses/by/4.0/). 